\title{
A PESQUISA DISCENTE NOS CURSOS DE GRADUAÇÃO EM BIBLIOTECONOMIA E CIÊNCIA DA INFORMAÇÃO'
}

\author{
César Augusto CASTRO2
}

\section{RESUMO}

Discute-se a importância da pesquisa discente nos cursos de graduação em Biblioteconomia e Ciência da Informação. Enfocam-se os diferentes tipos e os niveis de participação dos alunos em projetos de pesquisa. Aborda-se a monografía de conclusão de curso e o estágio como meios pelos quais os discentes buscam, a partir de referenciais teóricos e metodológicos, refletir criticamente sobre os problemas das Unidades de Informação.

Palavras-chave: Pesquisa Discente-Biblioteconomia; Ciência da Informação-Pesquisa Discente.

\begin{abstract}
Discusses the importance of research developed by undergraduate students at Brazilian Library and Information Science Schools, pointing out the different kinds and levels of participation. The course's final monograph and the in-service training are also focused as relevant research tools for students when searching for solutions to library and information problems.
\end{abstract}

Key words: Student's Research - Librarian Formation Course; Information Science Student's Research.

O aluno ao adentrar a universidade-pública ou privada - traz infinitas expectativas que devem ser atendidas de maneira adequada e plena, por todos aqueles que atuam como professores, gestores e apoio acadêmico. É evidente que diante da crise política, econômica e, principalmente, administrativa, o "ideal acadêmico", isto é, formar indivíduos teórica e tecnicamente competentes para atuar em um mercado competitivo, desigual e incerto torna-se cada vez mais uma atividade complexa, notadamente nas IES periféricas, que carecem de professores com máxima titulação, de programas de pós-graduação e de editoras universitárias com políticas de publicação relevante e forte e, ainda, com instituições estaduais de amparo aos projetos de pesquisa e extensão universitária - a exemplo da FAPESP -, entre outros fatores que distanciam as universidades da sociedade brasileira.

Se nas universidades que apresentam situação financeira e acadêmica diferente do quadro acima descrito, o desenvolvimento de investigação científica e extensionista é importante, naquelas é vital,

1. Trabalho apresentado na Reunião da ABECIN (Ex-ABEBD) realizada em maio de 2001, em Campinas, SP.

2. Professor adjunto do Departamento de Biblioteconomia e do Programa de Pós- Graduação em Educação da UFMA. Doutor em Educação pela USP. 
na medida em que contribui para ampliar os fazeres e os saberes cotidianos acadêmicos.

A primeira questão que considero crucial quando tratamos da temática Pesquisa Docente nos Cursos de Graduação é a não dicotomia entre Ensino, Pesquisa e Extensão, bem como a interdependência entre a pesquisa discente e a pesquisa docente. É evidente, que faço as devidas e adequadas distinções entre ambas e o papel dos agentes, mas não as hierarquizo, isto é, não separo o sujeito cognoscível do sujeito cognoscível, concebo-as como uma ação dialogal entre aqueles que desejam desvendar, descobrir, conhecer, construir e propor o novo teórico e prático.

"A educação assim encarada (como problemática, logo como princípio investigativo) é aquele que propicia desenvolver nos alunos o seu poder de captação e compreensão do mundo como realidade em processo, pensando-o e a si mesmo, sem dicotomizar este pensar da ação. A prática educativa problematizadora propõe aos homens e sua própria situação como um problema (um desafio) a ser encarado, vivendo à transformação. É, pois, uma educação conscientizadora na medida em que convida à tomada de uma posição dialética frente ao mundo, a transformar os homens em 'fazedores' da realidade, da História. É uma educação que convida à busca que começa no próprio homem e suas relações com o mundo - realidades inseparáveis - e se prolonga na reconstrução da realidade" (CANDAU, 1996, p.89).

Deste modo, acredito que a pesquisa discente orientada nesta perspectiva - da problematização contribuirá para formar o espírito científico nos jovens, mas principalmente ajudará a torná-los pesquisadores comprometidos consigo, com o outro e com o mundo, objetivando envidar esforços para minimizar as diferenças e desigualdades sociais, culturais e econômicas do país, sem contudo se abandonar o lado onírico e fascinante da ciência, como afirma Alves (2001, p.115): “A ciência é muito boa dentro dos seus precisos limites. Quando transformadora na única linguagem para se conhecer o mundo, entretanto, ela pode produzir dogmatismo, cegueira e, eventualmente, emburrecimento".

Este aluno-pesquisador, assim orientado, ao concluir sua vivência universitária não procurará obter respostas para os problemas - base de qualquer identificação - que enfrentará no cotidiano profissional sem recorrer aos procedimentos e metodologias de pesquisa. Assegura-se assim a necessidade da educação continuada - formal e informal - que é um dos meios mais adequados para garantir a relação mercado de trabalho, competência e sociedade.

Esta questão fica bem demarcada no texto da lei 9394/98, quando se reporta à finalidade da educação superior:

"[...] estimular a criação cultural e o desenvolvimento do espirito científico e do pensamento reflexivo, formar diplomados nas diferentes áreas do conhecimento, aptos para a inserção em setores profissionais e para participação do desenvolvimento da sociedade brasileira e colaborar na sua formação continuada, incentivar o trabalho de pesquisa e investigação cientifica, visando o desenvolvimento da ciência e da tecnologia da criação e difusão da cultura e, desse modo, desenvolver o entendimento do homem e do meio em que vive; promover a divulgação de conhecimentos culturais, cientificos e técnicos que constituem patrimônio da humanidade e comunicar o saber através do ensino e publicações ou outra forma de comunicação; suscitar o desejo permanente de aperfeiçoamento cultural e profissional e possibilitar a correspondente concretização, integrando os conhecimentos que vão sendo adquiridos numa estrutura intelectual sistematizadora do conhecimento de cada geração; estimular o conhecimento dos problemas do mundo presente, em particular 
os nacionais e regionais; prestar serviços especializados à comunidade e estabelecer com esta uma relação de reciprocidade; promover a extensão, aberta à participação da população, visando à difusão das conquistas e beneficios resultantes da criação cultural das pesquisas cientificas e tecnológicas geradas na instituição" (SOUZA; SILVA, 1997, p.71) (grifo nosso).

Observa-se no texto da LDB a nítida e interdependente relação entre a pesquisa, o ensino e a extensão - antes evidenciada - sem a qual o "ideal acadêmico", fragiliza-se de tal maneira que o predomínio de uma atividade desequilibra o sistema, trazendo conseqüências irremediáveis à criação cultural, ao pensamento crítico-reflexivo, ao desenvolvimento da qualidade material e social, da sociedade brasileira e da ciência, sendo que esta deve se voltar para os problemas nacionais e regionais, a fim de melhorar as condições principalmente da clientela carente, alijada historicamente das condições mínimas de sobrevivência.

Portanto, a articulação:"Ensino com extensão aponta para a formação contextualizada às agudas questões da sociedade contemporânea. Ensino com pesquisa aponta para o verdadeiro domínio dos instrumentos nos quais cada profissão se expressa, em seu próprio processo evolutivo" (PLANO, 2000, p.5). Este aspecto é de fundamental importância no momento atual, para os cursos de graduação, cujos projetos pedagógicos estão em processo de elaboração, baseados nas diretrizes curriculares. Estes projetos devem ser orientados para:

“a. oferecer ensino qualificado, promovendo atividades que instiguem, a investigação $e$ estimular a capacidade crítica, assegurando atualização cientifica, formação integral $e$ atendimento à demanda social.

b. promover a prática da pesquisa em todos os cursos de graduação, adotando-se politicas institucionais de pesquisa que atendam às novas exigências da graduação, sustentando o programa com dedicação dos docentes e apoio institucional aos alunos na forma de bolsa de iniciação científica e/ou outras estratégias;

c. promover a prática da extensão na graduação como componente indissociado do projeto pedagógico do curso, visando à formação mais adequada da cidadania. Este programa será sustentado com dedicação do docente e apoio institucional aos alunos" (Id. Ibid., p.15) (grifo nosso).

Nesta perspectiva, entendemos a pesquisa discente, independentemente de área e curso, como o meio pelo qual efetiva-se a relação saber-fazer-saber. Assim, a pesquisa assume papel relevante, na medida em que contribui para romper com aulas expositivas e reprodutivas do discurso alheio, trazendo para o espaço da aula contribuições essenciais reais e concretas, etc.. Assim atribuo algumas vantagens à participação e desenvolvimento de estudantes na pesquisa acadêmica, nos cursos de Biblioteconomia e Ciência da Informação, objetivando:

a. ampliar e aprofundar os saberes e as práticas pedagógicas de sala de aula. "Daí a necessidade de iniciar e "treinar" o aluno em atividades que constituem o cotidiano de todo o trabalho intelectual [...]: leitura, análise de textos, pesquisa bibliográfica, documentação, sinteses [...]" (SALOMON, 1999, p.15).

b. possibilitar um novo olhar sobre o campo da Biblioteconomia e Ciência da Informação.

À Biblioteconomia, historicamente tem sido atribuído maior relevância técnica que teórica. Isto tem ocasionado interpretações errôneas pela sociedade e, algumas vezes, pelos alunos. A técnica sem teoria é conhecimento vazio, e a teoria sem relação com a prática é conhecimento ingênuo. A pesquisa dará maior compreensão teórica, prática e técnica ao futuro profissional, que compreenderá de maneira mais ampla a natureza, os problemas e as possíveis soluções para as Unidades de Informação e para os 
referenciais teóricos da área e, principalmente para definir a favor e contra quem o profissional emprestará seu capital intelectual.

c. contribuir para a formação crítica e politicamente engajada com questões sociais, econômicas, culturais, científicas e tecnológicas: "Assim, a aquisição de conhecimentos deve ir além da aplicação imediata, impulsionando o sujeito, em sua dimensão individual e social, a criar e responder a desejos[...] capazes de gerar, aperfeiçoar tecnologias. Torna-se necessário desenvolver a habilidade de aprender recriar permanentemente retomando o sentido de uma educação continuada" (PLANO, op.cit, p.4).

d. despertar o interesse do aluno pela pesquisa científica.

Todas estas ações somente se concretizam se o processo for conduzido no sentido do aprender a aprender, em que o discente atua de modo ativo e cujo papel do orientador é conduzir, encaminhá-lo na leitura e na adoção de metodologias científicas adequadas para encontrar "verdades" que não sejam absolutas e abstratas: “ À concepção autoritária do conhecimento- verdade, abstração criada para dominar, contrapomos os conhecimentos dos homens, que os constróem em sua ação transformadora de transformar" (ALVES, 1993, p.76). Além de formar um futuro pesquisador ético e comprometido consigo, com o outro e com o mundo.

Cada vez mais, por necessidades várias, observo o interesse dos alunos, notadamente aqueles dos dois primeiros anos do curso de graduação, em participarem, junto aos professores, de projetos de pesquisa e de projetos de extensão: igualmente, noto o diferencial que os mesmos fazem entre o professor-professor e o professor-pesquisador e uma valorização do professor-pesquisador-autor, isto é, aquele que, além de suas atividades de ensino e pesquisa produz, e divulga sua produção intelectual e coletiva.
“É preciso, pois, dizer com todas as letras que o ambiente acadêmico adequado começa pelo professor, pois o aluno adequado é também função do professor adequado [...]. Diante de professor que aprende bem, estuda delicadamente, produz conhecimento sistematicamente, traz para os alunos textos seus, o aluno tem pelo menos exemplo edificante do que é aprender. Em contrapartida, diante de professores que apenas reproduzem aulas, dificilmente o aluno chega à idéia de que educação tem como objetivo fundamental gestar autonomia" (DEMO, 2000 p.95).

Por outro lado, observo nesses alunos inquietações múltiplas do tipo: Que profissão é esta? Qual o mercado de trabalho (convencional e emergente)?, Quais os critérios exigidos para atuar profissionalmente? São esses discentes que no cotidiano pedagógico trazem questões merecedoras de respostas e, por conseguinte, nos estimulam a driblar as barreiras comuns aos pesquisadores brasileiros, principalmente àquelas das universidades públicas periféricas.

Entendemos que a pesquisa discente segue em três dimensões: a primeira é a da Iniciação Científica, entendida como tal não somente a vinculada a programas como o PIBIC, mas toda atividade de pesquisa que objetiva ensinar os primeiros caminhos do saber científico aos alunos. Daí, dividi-la em três modalidades.

a. Iniciação científica institucional externa é aquela em que os alunos recebem recursos oriundos de instituições nacionais ( $\mathrm{CNPq}$, p.ex.) e internacionais.

b. Iniciação científica institucional interna, cuja origem dos recursos são advindos da própria instituição à qual o aluno está vinculado (por ex. os alunos que recebem bolsas da UFMA).

c. Iniciação científica voluntária. Esta modalidade é a que considero mais relevante, na 
medida em que o interesse do aluno centra-se principalmente na investigação e não no valor da bolsa, que muitas vezes se constitui no maior interesse, justificado face à escassez de emprego, mas que transforma a bolsa-pesquisa em bolsa-salário.

Outra modalidade de pesquisa discente é a da "constância", aquela que é contínua em todo o fazer/saber pedagógico e que ocorre em sala de aula, quotidianamente. Assim, abandona-se a transmissão de conteúdos unilaterais e acabados e propicia-se o desenvolvimento da capacidade cognoscitiva dos alunos e, por conseguinte, a formação crítica e criadora frente à realidade e ao cotidiano da vida social (LIBÂNEO, 1994).

Para tanto, é condição primária desconstruir a imagem de aluno "...como sendo alguém subalterno, tendente a ignorante, que comparece para escutar, tomar nota, engolir ensinamentos, fazer provas e passar de ano" ( DEMO,1998, p.14).

Todas estas atividades culminam com o Trabalho de Conclusão de Curso, (denominado, também, de Monografia de Graduação ou Monografia de Conclusão de Curso) em que o aluno, de posse de instrumentais teóricos-metodológicos adquiridos no decorrer do curso, investiga um aspecto do seu real-teórico ou prático. Entretanto, algumas vezes este aluno, quando conduzido inadequadamente encontra no TCC o maior entrave para concluir a Graduação. Na Universidade Federal do Maranhão, em geral, e no Curso de Biblioteconomia, em particular, a monografia tem-se constituído no ponto central de retenção dos alunos, apesar de todos os esforços enveredados pelos docentes no sentido de conduzir as atividades de maneira adequada e prática, sem, contudo, perderem o caráter e o rigor acadêmico e científico inerente ao trabalho científico.

Esta é a problemática que os outros Cursos, possivelmente, enfrentam e que só se modificará quando a investigação científica se constituir em prática comum e cotidiana entre professores e alunos.

Tenho observado que alunos com experiências positivas de pesquisa durante a sua trajetória aca- dêmica encontram menores dificuldades para escolher um tema, formular e delimitar um problema, estabelecer hipóteses e variáveis e, principalmente, conduzir adequadamente a sua fundamentação teórica do que aqueles que não tiveram a mesma experiência.

Um espaço privilegiado de pesquisa é o estágio (extracurricular e/ou curricular), que infelizmente é tomado como um momento - geralmente no final do curso - de exercício prático, ao contrário do que deveria ser: uma oportunidade singular para o aluno conhecer uma dada realidade e propor com base em conhecimentos teóricos e práticos soluções, para os problemas costumeiros em bibliotecas, arquivos e outras Unidades de Informação.

Um outro ponto que considero importante é a participação de alunos de várias áreas em um mesmo projeto, cujas vantagens são inúmeras, sendo a principal a troca de saberes e compressões mais amplas em torno das fronteiras e interdependência de um campo de saber com os demais.

Estes são, portanto, o modo como vejo, observo e analiso a pesquisa discente no Curso de Graduação em Biblioteconomia e Ciência da informação, tomando, evidentemente o da UFMA como meu referencial de análise.

\section{REFÊRENCIAS BIBLIOGRÁFICAS}

ALVES, Rubem. Entre a ciência e a sapiência: o dilema da educação. São Paulo: Loyola, 2001.

BRASIL. Ministério da Educação. Plano Nacional de Educação. Disponível em: http// $w w w$. mec.gov.br/sesu/planograd. htm. Acessado em 18 jul. 2001.

CANDAU, Vera Maria. Rumo a uma nova didática. 8. ed., Petrópolis: Vozes, 1996.

DEMO, Pedro. Saber pensar. São Paulo: Cortez, 2000.

FUNDAÇÃO GETULIO VARGAS divulga pesquisa mapa do fim da fome. Disponível em http//www. fgv. gov.br. Acessado em 18 jul. 2001.

LIBÂNEO, José Carlos. Didática. São Paulo: Cortez, 1994.

SOUZA, Paulo Natanael P. de e SILVA, Eurides Brito da. Como entender e aplicar a nova LDB (Lei N ${ }^{\circ}$ 9.394/96). São Paulo: Pioneira,1997. 